\title{
DE TIJDREKENING BIJ DE LANDAK-DAJAKS IN DE WESTERAFDEELING VAN BORNEO
}

Door M. C. SCHADEE.

\section{§ 1 . Ja a r telling.}

De tijdrekening der Dajaks is zeer primitief. Eene geregelde jaartelling kennen zij niet, d. w. z. zij hebben geen vast punt in de historie aangenomen, waarop deze een aanvang zou nemen.

Zij rekenen slechts bij geslachten (katoeroenan) waarbij die van de Maleische radja's van het landschap of ook wel van eigen voorouders tot maatstaf dienen.

\section{$\S 2$. Jaarverdeeling.}

Eene regelmatige verdeeling van het jaar in maanden en weken heeft evenmin plaats; men geeft echter ${ }^{1}$ de tijden van het jaar aan naar den stand van het padi-gewas.

Men vermeldt dus, om den tijd van de eene of andere gebeurtenis aan te geven, de periode van den rijstbouw, tijdens welke het feit plaats had bijv: "mijn broeder is het vorige jaar gestorven tijdens het branden der velden.»

Van het gepasseerde jaar sprekende zeggen zij ook: "het jaar waarvan thans (de rijst) gegeten wordt. ${ }^{2}$

Het jaar wordt dus gerekend te beginnen, zoodra de eerste maatregelen genomen worden voor de ontginning der nieuwe rijstvelden.

Ofschoon de Dajaks een jaar dus niet met een bepaald aantal dagen afsluiten is hunne tijdrekening toch in zooverre geregeld, dat de stand der sterren den tijd der veldwerkzaamheden aangeeft. Hun jaar is dus het zonnejaar.

1. Evenals vele andere heidensche stammen in den Indischen Archipel zulks doen. Vergelijk „De Handleiding voor de vergelijkende volkenkunde van Ned. Indie door Dr. G. A. Wilken blz. 119 en diens „Iets over naam. geving en eigennamen bij de Alfoeren der Minabasa in Tijdschrift voor Ind. T. L. en V.kunde, Deel XXII."

"De Maleiers zeggen: "taoen jang dimakan ini." 
$\S$ 3. Sterrenbeelden.

De sterrenbeelden, welke daartoe dienst doen, zijn twaalf in getal, in een rij langs den hemel-evenaar gelegen; echter geen aaneengesloten gordel vormend.

Het zijn de volgende.

1. Bintang toedjoeh = zeven sterren, ook kartika genoemd, de Pleiaden. ${ }^{1}$

2. Rahang $=$ kinnebakken, de Hyaden. ${ }^{2}$

3. Danau $==$ meer, de Vloed Eridan.

4. Pěti = varkens- of wilde beestenval, de Orion. ${ }^{3}$

5. Toré, de naam van een klein soort eetbare riviervisch, Sirius (alpha canis), een der schitterendsche sterren van den Zuidelijken Sterrenhemel.

6. Tamano. De beteekenis van dit woord is ons onbekend.

1 Ook in Landak is de legende omtrent het verdwijnen van een der zeven sterren bekend.

[Grimm, Deutsche mythologie II 607 vlgg. III 213 vlgg.

Dupuis, Origines des cultes III 235 vlg.

Schaank, Iets over de Dajaksche sterrenkunde, Tijdschrift v/d Ind. T. L. en V kunde deel XXXII p. 435.

Dr. C. Snouck Hurgronje. De Atjehers - Deel I p. 278.]

De aldaar medegedeelde pantoen luidt in Landak: "Bintang toedjoeh tinggal anam" "Djatoh menimpa di mandjapahit” „Batang toeboeh rasa demom" "Sirih pinang dimakan pahit." De laatste regel ook: kalau kěrtemoe baharoe bais" "Zeven sterren zes zijn overgebleven" („Een) is gevallen te mandjapahit" "mijn lichaam voelt koortsig aan" „Betel smaakt mij bitter." Inplaats van de laatste regel. „Wanneer ik haar ontmoet dan is het weer in orde."

2 De Rahang is vermoedelijk het kinnebakken van het Hindoesche sterrenbeeld de Stier, waarvan de Hyaden een deel uitmaken.

3 De pati of pĕti, welke bij de Landak-Dajaks ook koebó heet en bij de Landak-Maleiers ook "bentiang”, is ingericht als de Javaansche wělěng, met dit onderscheid, dat wanneer de val in werking komt de gespannen boomstam niet een geweer doet afgaan, maar met kracht een speer in het lichaam van het zwijn drijft. Vergelijk De wělĕng door G. in het Tijdschrift voor het Binn. Bestuur, Deel II blz. 186. Afbeelding en beschrijving van de Dajaksche pĕti zijn te vinden in Ling Roth, The natives of Sarawak Vol. I p. 437 sqq.

Opmerkelijk is het dat Orion bij de Grieken een reusachtig jager was, die op de Asphodelosweide het wild vervolgt. (Andree, Ethnographische Vergleiche und Paralellen. Bastian, Geographische und Ethnographische Bilder p. 126.)

Alsmede dat deze ster ook bij de Banaren, een bergvolk van Achter-Indië, een val voorstelt. (Andree). 
Tamano stelt een driehoek voor gevormd door $\delta$ en $\varepsilon$ canis en $\eta$ argus. Ook de beide volgende beelden behooren tot het schip Argo.

7. Е̌nsoelit, naam van een vogel, welke vaak groote schade aan de te velde staande padi toebrengt. Ěnsoelit bestaat uit $\breve{\zeta}$ en $v$ argus. $v$ argus heet ook pipit $=$ musch. ${ }^{1}$

8. Oedang galah = De Groote Zeegarnaal. Dit beeld bestaat uit vier sterren, welke evenals het Zuiderkruis in den vorm van een vlieger gelegen zijn. De beelden zijn bijna geheel gelijkvormig, beide een weinig scheef; de Oedang Galah is echter grooter dan het oostelijk daarnaast gelegen Zuiderkruis. Wij hebben het wel eens "het Valsche kruis» hooren noemen. Het zijn, $\iota, \varepsilon$ en $\delta$ Argus benevens een vierde ster (de top van den vlieger) waarvan wij den naam te vergeefs op de sterrenkaart gezocht hebben.

9. Prahoe-Paré. (= Prauw-Rog), het Zuiderkruis. De prauw wordt gevormd door $\alpha$ en $\beta$ centauri en de zich juist voor den boeg van het vaartuig vertoonende reusachtige $\operatorname{rog}$ door $\alpha, \beta$, $\gamma$ en $\delta$ crucis (de vier sterren van het eigenlijke Zuiderkruis).

10. Djangka. Dit sterrenbeeld vormt met de beide laatste sterrenbeelden van den Dajakschen dierenriem ons sterrenbeeld: de Schorpioen. In zijn geheel is dit beeld echter niet als Bintang kala aan de Landak-Dajaks bekend.

De djangka wordt gevormd door $\beta, \delta, \pi, \varrho, \sigma, \alpha, \tau$ en $\varepsilon$ scorpiï.

Dit beeld wordt door de Dajaks ook wel vergeleken met een klapperboom; de stam wordt dan gevormd door de vier laatste sterren, terwijl de vier eerste klappers voorstellen; Anstares ( $\alpha$ scorpii) is een bijen nest, dat de op klappers beluste knapen belet den boom te beklimmen.

11. Dara bagoetoe ${ }^{2}=$ de Luizende Meisjes. Waar de kromming van den Staart van den Schorpioen aanvangt, bevinden zich twee sterretjes vlak bij elkaar, 1 en 2 scorpiī. Dit zijn de Dara bogoetoe. Men wachtte er zich dus voor deze "maagdjes» te vereenzelvigen met onze tweelingen.

12. Pradah. Met dit woord wordt de steel bedoeld, waaraan de inlanders hun bělioeng (een soort beitel) met rotan bevestigen, om dan als een bijl tot kappen te gebruiken.

1 Do rijstdiefjes liggen vlak bij Sirius, door de Romeinen ook „Invidum agricolis" genoemd = die de landbouwers schade brengt.

${ }^{2}$ goetoe Daj. = koetoe Mal. = luis, dara = maagd. 
Hyaden

\section{Orion}

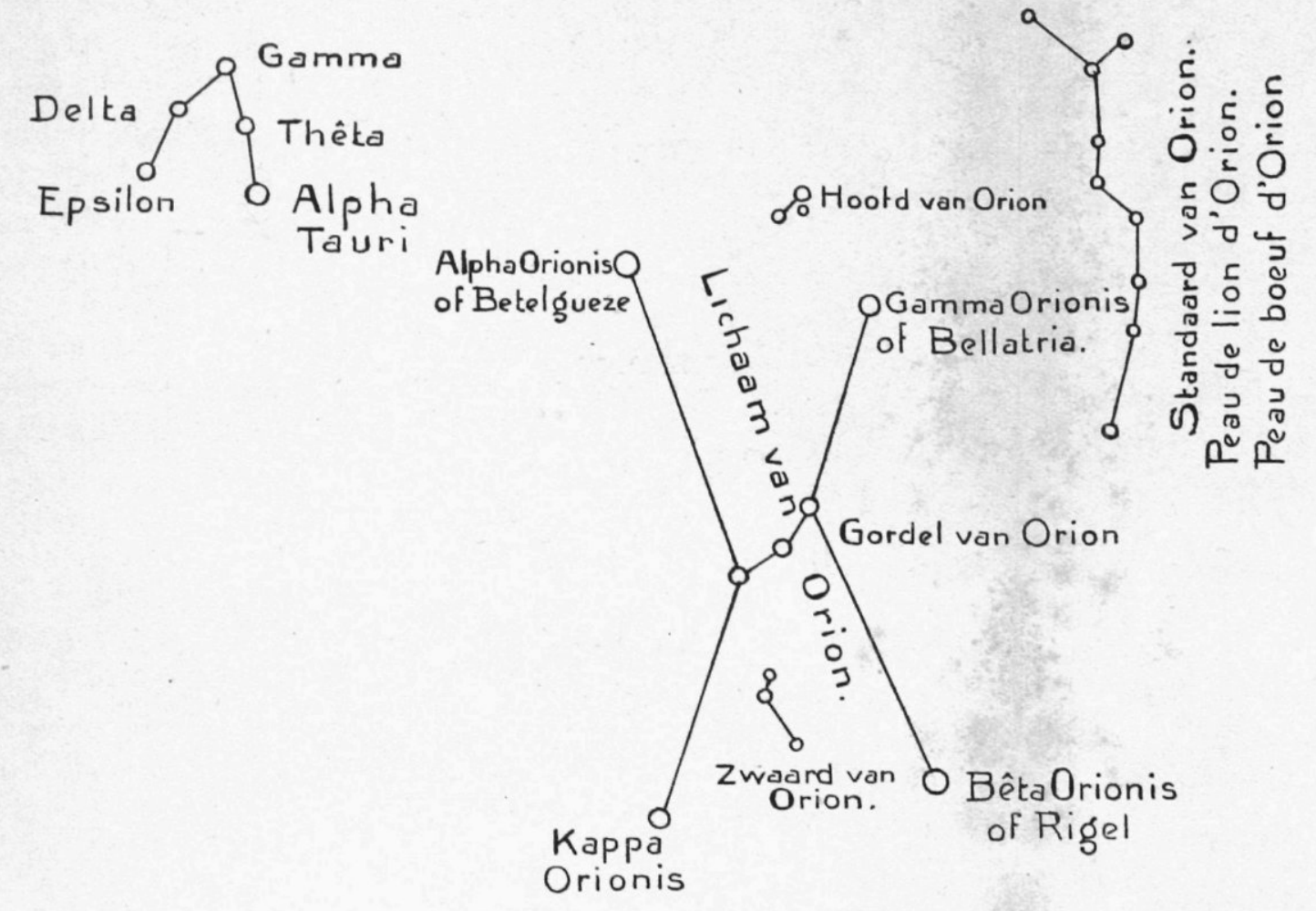

\section{Schorpioen.}
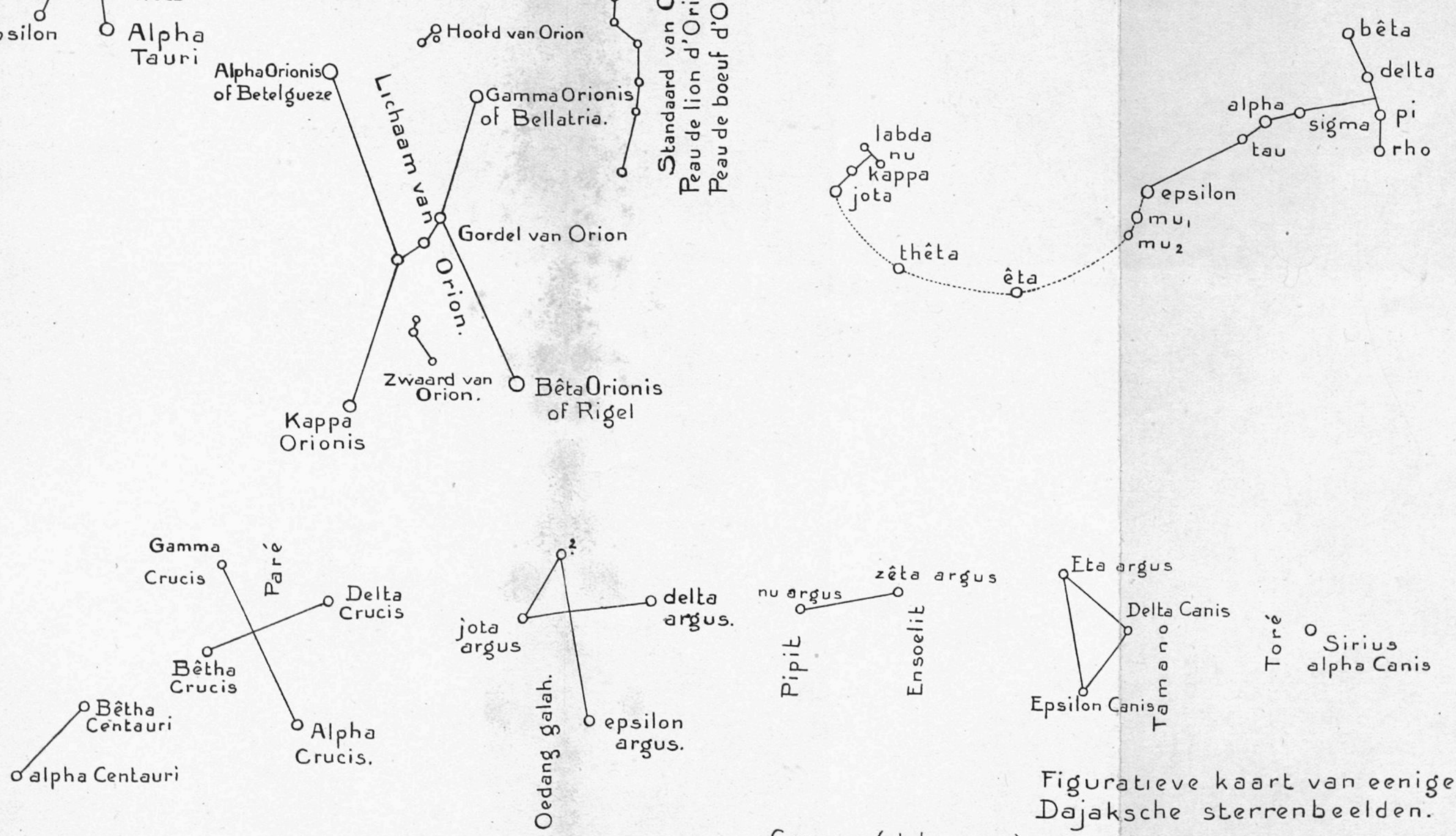

- Canopus (alpha argus) 
De gaboes of piabong, het deel der pradah, dat men in de hand houdt, wordt gevormd door $\iota$ en $*$ scorpiï, de krawat, waaraan de bellioeng vastgebonden wordt door $\lambda$ en $v$ scorpii.

Hiermede zijn de twaalf beelden van den Dajakschen sterrengordel genoemd. De kennis ervan is nog slechts bij ouden van dagen te vinden; het jongere geslacht is tevreden wanneer het de Pleiaden en de Orion aan den hemel kan aanwijzen.

Volgens het volksgeloof zijn deze sterren door de Dewata's aan den hemel geplaatst, opdat de menschen daarnaar hun rijstbouw kunnen regelen, waarom ze bij de Dajaks «bintang pangada» of "adaän» d. w. z. "teeken» genoemd worden.

Alle andere sterren zijn volgens hen slechts «kinderen», waarmede zij geene rekening hebben te houden.

Eene uitzondering hierop maakt nog de "Groote Beer» welke de iringan d.i. »begeleider» wordt genoemd, n. l. van de "bintang torè (Sirius), als ongeveer gelijktijdig met deze aan het uitspansel verschijnende en ondergaande.

Zooals reeds werd opgeteekend vormen de bintang pěngada geen aaneengesloten gordel. De afstand tusschen den Schorpioen waartoe de Prada behoort, en den Stier, waarvan de Pleiaden deel uitmaken, welke sterrenbeelden dus aan den Landakschen sterrenreeks en aan den Griekschen dierenriem gemeen zijn, wordt in dezen laatsten door vijf andere sterrenbeelden: de Schutter, Steenbok, Waterman, Visschen en Ram ingenomen.

Dit baart echter den Dajaks geene zorgen.

In den tijd toch, dat deze sterren zich des morgens kort voor zonsopgang - dit is het tijdstip, waarop de Dajaksche astronomen hunne waarnemingen aan den hemel doen - even boven den oostelijken horizon vertoonen ' is dc rijstoogst afgeloopen, en wordt de tijd óf met niets doen óf met het geven van feesten, met hunne lange voorbereidingen en even lange naweeën gepasseerd, totdat het verschijnen der Pleiaden hieraan een einde maakt.

Bij verdere vergelijking van de sterrenreeks der Landak-Dajaks met den Griekschen Dierenriem, zien wij dat die Dajaks de brug om van de Orion op de Schorpioen te komen genomen hebben over het schitterende sterrenbeeld van Sirius, over den driehoek gevormd door Tamano, door de juist in de richting liggende "Rijstdiefjes, door het "Valsche kruis» en het ware "Zuiderkruis, hetgeen niemand verwondering zal baren, die den 
schoonen gordel, door deze sterren aan den Zuidelijken Hemel gevormd, aanschouwd heeft en zich bewust is van de aantrekkingskracht, die hij op de bewoners van den evenaar moet hebben uitgeoefend.

\section{§ 4. Hoogtemeting der sterren.}

Eigenaardig is de manier, waarop de sterrenkundigen onder de Dajaks de hoogte boven den horizon aangeven. Zij nemen daarvoor vier standen aan, te weten:

$1^{\text {e. }}$ tarima,

$2^{\text {e. }}$ soesoer gălāng;

$3^{\text {e. }}$ karoet;

4. laboeh tangkoeloes.

Tot verklaring dezer woorden veronderstellen wij dat een Dajaksch patriarch, die zich van den stand zijner "pěngada» wil verzekeren, des morgens bij het onzichtbaar worden der meeste sterren, met het gelaat naar het Oosten gewend, op een punt vanwaar het uitzicht vrij is, op den grond is gezeten.

Eerste stand:

Hij strekt zijn rechterarm recht voor zich uit, alsof hij iets wil aannemen (tarima). Het sterrenbeeld, dat zich dan in de richting van den arm bevindt, is in den stand "tarima.»

Nemen wij aan, dat dit het beeld der Pleiaden is, dan zegt de Dajak, dat de tijd voor het zoeken der plaats waar hij zijne padivelden wil aanleggen ( $\mathrm{m}$ engawa) daar is.

Sommige Dajaks kennen nog een stand, welke aan het "tarima» voorafgaat, n.l. "ng ă rom po». Rompo = gebladerte; ngărompo iets in het gebladerte zien, de ster dus tusschen de bladeren van het bosch te voorschijn zien komen. '

Tweede stand.

Onze Dajaksche astronoom ziet het sterrenbeeld op hetzelfde tijdstip van den morgen iets hooger boven den horizon. Om het aan te wijzen, moet hij den uitgestrekten arm opheffen, zijn polsring glijdt langs den arm naar beneden naar den elleboog (soesoer gělang).

De methode om op deze wijze de hoogte der sterren aan te geven is ook in Atjeh in gebruik. ${ }^{2}$

1 Ditzelfde beeld vindt men terug in de hieroglyphe waarmede de Chineezen "het oosten" aanduiden. Zie Schlegel, Uranographie Chinoise p. 90.

2 Dr. C. Snouck Hurgronje. Deel I blz. 279. 
Bevinden zich de Pleiaden in den stand van het soesoer gělang, dan is het tijd voor het boschkappen.

Derde stand.

Het sterrenbeeld is weer hooger geklommen. Om het te zien, moet onze Dajak zijn blik naar boven werpen; zijn voorhoofd rimpelt zich (karoet). ${ }^{1}$

Het is tijd het gekapte bosch te branden.

Bij de Dajaks van het landschap Melliau wordt deze stand door een ander beeld weergegeven, en heet bij hen «langgar soeman» d. i. het schuin over het vuur staan van een soeman d. i. een bamboekoker gevuld met kleefrijst en water, welke gaar gestoomd moet worden.

Vierde stand.

Het sterrenbeeld bevindt zich in het culminatiepunt. Onze astronoom moet om het te zien, zijn hoofd zoover achterover buigen, dat zijn mutsje afvalt. (laboeh tangkoeloes).

Bij de Meliau-Dajaks heet dit tanggal labong, hetgeen hetzelfde beteekent. Labong is een hoofddoek of hoofdring van geklopt boomschors (těmbĕran) ${ }^{2}$ In dezen stand is het zaaitijd.

Reeds in het laatst van Mei hebben de Pleiaden des morgens om half zes ure eene hoogte van $10^{\circ}, 11 \mathrm{Juli}$ is de verheffing $45^{\circ}$ en 12 Augustus $90^{\circ}$.

De Orion is des morgens om half zes ure pas in het laatst van Juni te zien, 11 Juli staat zij 25, 12 Aụgustus $70^{\circ}$ en 5 September $90^{\circ}$ hoog.

Een sterrenbeeld doorloopt de vier standen dus binnen drie maanden.

Het is duidelijk dat, wanneer de Pleiaden in den stand karoet staan, ook de Hyaden, Eridan en de Orion in de lagere standen ook reeds zichtbaar zijn, daar deze sterrenbeelden dicht op elkaar volgen.

1 Dit herinnert aan de Maleische uitdrukking "angkat kĕning" = "de wenkbrauwen opslaan, ongeveer 8 uur 's morgens, wanneer men de wenkbrauwén even opslaande de zon ziet. Zie de Mal. Woordenboeken.

2 Wij zien hieruit dat de Dajaksche dierenriem anders is ingericht dan de onze. Wanneer wij zeggen dat de z̧on in het een of ander sterrenbeeld staat, is het de bedoeling, dat de zon in de richting van dat sterrenbeeld te zien is. De ster gaat dan tegelijk met de zon op en onder, bevindt zich overdag aan den hemel en is dus dan alleen met het gewapend oog te onderscheiden. Het is begrijpelijk dat onbeschaafde volken deze methode niet hebben gevolgd. 


\section{$\S$ 5. Maanphases.}

Van het bovenstaande onderwerp afstappende, gaan wij thans over tot de verdere bespreking van de Dajaksche tijdrekenkunde.

De dagen der week zijn den Dajak onbekend; hij bepaalt den tijd alleen naar den dag der maand, en let daarbij in het bijzonder op de schijngestalten van de maan.

Evenals de maan bij vele volken nog in bijgeloovige vereering staat, en van invloed wordt geacht op verschillende omstandigheden des levens, is dit het geval bij de Dajaks, welke in alle natuur-verschijnselen een bijzondere werking der hoogere machten zien, waarmede zij goed doen, bij voortduring rekening te houden.

Sommige maanphases worden gunstig genoemd voor sommige verrichtingen, andere minder gunstig en weer anderen bepaald ongunstig. ${ }^{1}$ Vooral bij handelingen, welke op den landbouw betrekking hebben, wordt op de maangestalten gelet.

Bij twee stammen der Landak-Dajaks stelden wij een onderzoek in naar de namen der schijngestalten n. 1 . bij de Temilah- of Sepatah-Dajaks en bij de Dait-Dajaks, waarvan wij den uitslag hieronder mededeelen.

\section{Sepatah-Dajaks}

Eerste dag na nieuwe maan . boelan ségó tweede " " " herap middelste dagen van nieuwe maan 》 lima laatste dagen van nieuwe maan » kadang eerste dag of eerste twee dagen

van eerste kwartier. . . . doewa middelste dagen . . . . . $\begin{cases}\text { paoes } \\ \text { kira }\end{cases}$ laatste dagen . . . . . . . » boedjang " boedjang volle maan eerste dag. . . . " aja " noemas

" middelste dagen.. " ripan "klaman

» laatste dagen . . . " ngaloewang " perboeët laatste kwartier eerste dag . . » doewa " doewa

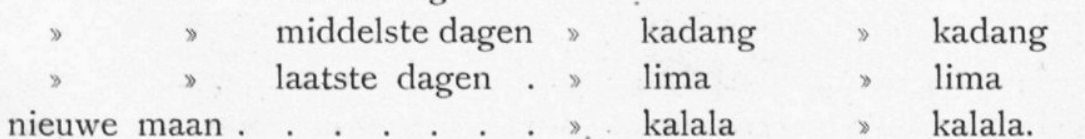

\footnotetext{
1 Zie over het kiezen van dagen Andree 1.c. pag. 1 sq, en vooral ter vergelijking "Het geven van namen aan de kinderen bij de Bataks, Indische Gids 1895 p. 817.
} 
Daar de tijd, welken de maan noodig heeft om van de eene phase in de andere over te gaan, verschilt naar den tijd van het jaar, is ook het aantal dagen of liever nachten, waarin de maan zich in de eene of andere phase vertoont niet in vaste cijfers uit te drukken.

Van nieuwe maan tot eerste kwartier doorloopt zij echter de schijngestalten, welke bij de Dait-Dajaks boelan kawat, boelan lima, en boelan kadang heeten.

Is het op den eersten van een onzer maanden nieuwe maan en den achtsten eerste kwartier dan zal het twee dagen bo ela n kawat, twee dagen boelan lima en twee dagen boelan kadang zijn.

Wanneer echter eerste kwartier pas op den negenden valt, dan zal het bijv. twee dagen boelan kawat, drie dagen boelan lima en twee dagen boelan kadang zijn,

Boelan kălālā heet eigenlijk het tijdstip van den overgang van de oude in de nieuwe maan. Men maakt daarbij onderscheid tusschen kalālā mati en kalālā hidoep, naargelang de maan nog afnemende of reeds wassende is.

Om boelan lima, boelan kadang, boelan doewa van de wassende maan te onderscheiden van de afnemende maan, voegt men er respectievelijk de woorden $\mathrm{nai}^{\mathrm{s}}$ en $\mathrm{njoeroet}$ of mati ook wel poelang aan toe.

Om den eersten of tweeden dag van zekere phase aan te duiden, bezigt men de woorden moeda (jong) en raja (groot) bijv. boelan boedjang moeda, boelan boedjang raja.

Den eersten noemt men ook wel doedoes, zoo is boelan doewa doedoes de eerste dag van boelan doewa.

Boelan doewa naï is dan de tweede dag van boelan doewa.

$\S 17$. Geluk-en ongelukaanbrengende maanphases.

Van deze dagen of tijdstippen nu gelden in het algemeen die van de wassende maan als gelukkiger dan die van de afnemende maan. Overeenstemmend in de bepaling ervan zijn de verschillende stammen echter niet.

De dagen van de boelan lima worden overal als zeer gelukkig aangemerkt, vooral van de boelan lima nai s.

Ook boelan doewa is een gelukkige periode. Boelan $\mathrm{kad}$ a ng (hetzij wassend of afnemend) geldt algemeen als omineus.

De boelan klaman periode (Dait-Dajaks) is van veel gewicht 
bij den veldarbeid. De opvolgende dagen van de boelan klaman noemt men:

boelan klaman tikoes,

\begin{tabular}{|c|c|c|}
\hline & 》 & boentas, \\
\hline & 》 & pasas, \\
\hline 》 & 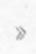 & tamoros, \\
\hline 》) & 》 & boeboe \\
\hline 》 & 》 & ampangos, \\
\hline & » & impimpé, \\
\hline 》 & $\rightarrow$ & pěrboeët. \\
\hline
\end{tabular}

Boentas $=$ soort sprinkhaan, pasa $^{5}=$ een rups met wit lichaam en roode kop, na hevigen regen te voorschijn komende en de kruin van de padi afvretend. tamoros $=$ een rups met witte kop, rood behaard, boeboe ${ }^{s}=$ kleine zwarte torretjes in reeds geoogste padi voorkomende, ampango ${ }^{5}=$ walang s ang it (lepto corisa acuta Thunb) met groene vleugels, im pimpé Daj. = impé Mal. een soort in het water levend insect, dat aan de wortels van moeras-padi knaagt, pěrboeët = antara, tusschen, tusschentijd.

Op de boelan klaman-dagen wordt bijzonder gelet bij het mangawah d. i. het met behulp van vogel-orakels uitzoeken van den besten grond voor het aanleggen van een ladang.

Wie dit bijv. doet op boelan klaman tikoes kan zeker zijn dat zijn rijstveld door een muizenplaag geteisterd zal worden, op boelan klaman ampangos zal de walang sangit de padi vernielen. Wie dat echter waagt op boelan klaman perboeët kan niet anders verwachten dan dat de doos van Pandora gevuld met al het bovengenoemde ongedierte over zijn te veld staanden oogst zal uitgestort worden.

De Termilah-Dajaks letten niet alleen op deze omineuze dagen bij het mangawah, maar zullen ook in die dagen niet tot boschkappen overgaan, de Dait- en Menjoeké-Dajaks laten er zich niet door weerhouden de laatste werkzaamheid te verrichten.

Als minder gunstige dagen worden verder aangemerkt b oelan kawat bij de Dait-Dajaks of ségo en hérap bij de TémilahDajaks.

Ook boelan kira; boelan boedjang, boelan aja, boelan ripan, boelan ngaloewang en boelan kalala staan bij laatstgenoemde Dajaks minder goed aangeschreven; de Dait-Dajaks verbinden echter aan boelan paoes, boelan 
boedjang, boelan noemas en boelan kalala geene pantangans.

Bij de Menjoeké-Dajaks leerden wij slechts volle maan en boelan kadang als gevaarlijke dagen kennen.

Huwelijken worden bijna overal voltrokken op boelan lima na nieuwe maan. Op dien dag zal men ook een begin maken met den bouw van eene nieuwe woning.

Het bijgeloof wil dat op boelan paoes alle sappen in planten en boomen zuur zijn; daarom zal men zich op dien dag nooit bezighouden met $\mathrm{m}$ a n oeba, d. i. visschen met behulp van het bedwelmende sap van den toeba-wortel.

Ook het zoeken van boomschors laat men op dien dag na, daar de schors dan moeilijker loslaat dan op andere dagen. 